\title{
Mineralization of iron oxide by ferritin homopolymers immobilized on $\mathrm{SiO}_{2}$ nanoparticles
}

\section{Daniel Carmona}

Advanced Ceramics, University of Bremen, Bremen, Germany

Laura Treccani

Petroceramics SpA, Stezzano, Italy

Monika Michaelis

Hybrid Materials Interfaces Group, University of Bremen, Bremen, Germany

\section{Steffen Lid}

Hybrid Materials Interfaces Group, University of Bremen, Bremen, Germany Christian Debus

Physical Chemistry, University of Konstanz, Konstanz, Germany
Lucio Colombi Ciacchi

Hybrid Materials Interfaces Group, University of Bremen, Bremen, Germany Kurosch Rezwan

Advanced Ceramics, University of Bremen, Bremen, Germany

Michael Maas

Advanced Ceramics, University of Bremen, Bremen, Germany

(corresponding author: michael.maas@uni-bremen.de)

(Orcid:0000-0002-2352-4822)

The iron storage protein ferritin is well known for its ability to mineralize iron oxides in its interior cavity. In this study, the authors investigated the mineralization behavior of $\mathbf{H}$ and $\mathrm{L}$ ferritin homopolymers assembled from individual subunits. The authors' approach included molecular dynamics simulations, which suggested that ferritin subunits arrange themselves on silica surfaces with the active side facing away from the interface, although non covalent adsorption interactions might be weak. In experimental studies, the nucleation of iron oxide nuclei could be observed at ferritin homopolymers which were covalently immobilized through the EDC/NHS strategy at the surface of silica nanoparticles. Mineralization was initiated by the addition of ammonium iron (II) sulfate hexahydrate $\left(\left(\mathrm{NH}_{4}\right)_{2} \mathrm{Fe}\left(\mathrm{SO}_{4}\right)_{2} \cdot 6 \mathrm{H}_{2} \mathrm{O}\right)$ as the source of iron ions and trimethylamine $\mathrm{N}$-oxide as the oxidant. The results demonstrate that immobilized $\mathrm{H}$ and $\mathrm{L}$ ferritin homopolymers on silica surfaces are able to induce the formation of a cohesive thin film of magnetic iron oxide crystals (magnetite and/or maghemite).

\section{Notation}

c the molar concentration of a peptide

$H \quad$ applied field strength

$l \quad$ the path length of the quartz cuvette

$M \quad$ sample magnetization

$n$ the number of amino acids of the ferritin protein

$T_{\mathrm{b}} \quad$ blocking temperature

$\theta_{\text {MRE }}$ mean residue ellipticity

$\theta_{\text {mdeg }}$ raw measured circular dichroism signal

\section{Introduction}

Naturally occurring biomineralizing systems, which are able to generate a wide variety of inorganic materials with intricate structures and distinctive properties, have led to the development of bioinspired approaches and new strategies for the synthesis and assembly of innovative, functional nanomaterials. ${ }^{1-6}$ For example, biomimetic approaches have been considered to develop magnetic materials for medical and diagnostic applications or high-density data storage. ${ }^{7}$ One of the most studied biomineralizing systems is represented by ferritin (Fn). Fn is a class of ubiquitous cage proteins of $900 \mathrm{kDa}$ and consisting of 24 helical subunits which are arranged in a spherical shape with a diameter of about $12 \mathrm{~nm}$ around a hollow cavity. When Fn is not loaded with iron oxide, it is an empty shell called apoferritin (apo-Fn; $480 \mathrm{kDa}$ ) which can be filled with up to 4500 iron $(\mathrm{Fe})$ atoms as a crystalline iron oxide hydrate to control iron homeostasis. ${ }^{8,9}$ In the case of vertebrate Fn, the proteins are composed of varying amounts of two different subunits, termed ' $\mathrm{H}$ ' (heavy chain) and 'L' (light chain). Although the two subunits share $55 \%$ of their amino acid sequence, they have different functions. The $\mathrm{H}$ subunit has ferroxidase catalytic activity and incorporates iron (II) into the protein cavity from the surrounding medium through channels in the quaternary structure of Fn. The L subunit is mainly involved in ferrihydrite crystal nucleation as it can rapidly catalyze the oxidation of iron (II) to iron (III). ${ }^{8-11}$ Isolated Fn subunits of a single type $(\mathrm{H}$ or $\mathrm{L})$ readily assemble into $\mathrm{Fn}$ homopolymers which are exclusively composed of the respective subunit. ${ }^{12} \mathrm{Fn}$ is remarkably robust, as it remains stable at relatively high temperatures (up to $85^{\circ} \mathrm{C}$ ) and over a wide $\mathrm{pH}$ range $(2 \cdot 0-12 \cdot 0$ ) for longer time periods. Based on these characteristics, whole cages of Fn, apo-Fn or engineered Fn homopolymers consisting of only $\mathrm{H}$ or $\mathrm{L}$ chains have been used as biotemplates for the spatially constrained synthesis of various metal and metal oxide nanoparticles ${ }^{13-15}$ and two-dimensional (2D) nanoarrays. ${ }^{16-18}$

In this study, the authors immobilized Fn homopolymers as a dense coating on silica nanoparticles to investigate the formation of cohesive magnetic iron oxide films at the surface of these particles. The experimental study is supplemented with simulation experiments, which investigate whether the immobilization of Fn subunits - that is, the constituents of the immobilized proteins - should be possible while retaining their mineralization activity. The authors used Fn 
homopolymers to be able to correlate the experimental findings to the simulation more clearly. Since protein immobilization is critical for a meaningful analysis of the mineralizing properties of the functionalized particles, immobilization was realized both by nonspecific adsorption (physisorption) and by covalent binding using the zero-length cross-linking system $\mathrm{N}$-(3-dimethylaminopropyl)- $\mathrm{N}$ ethylcarbodiimide hydrochloride (EDC)/ $N$-hydroxysuccinimide (NHS) (Figure 1). ${ }^{19-21}$ Prior to protein immobilization, the silica particle surfaces were functionalized with either (3-aminopropyl) triethoxysilane (APTES), which creates positively charged amino $\left(-\mathrm{NH}_{2}\right)$ groups, or 3-(triethoxysilyl)propylsuccinic anhydride (TESPSA), which results in the formation of negative carboxyl $(-\mathrm{COOH})$ groups. ${ }^{22}$ After immobilizing Fn on the silica particles, the synthesis of iron oxide using ammonium iron (II) sulfate hexahydrate $\left(\left(\mathrm{NH}_{4}\right)_{2} \mathrm{Fe}\left(\mathrm{SO}_{4}\right)_{2} \cdot 6 \mathrm{H}_{2} \mathrm{O}\right)$ as a source of iron ions and trimethylamine $\mathrm{N}$-oxide $\left(\mathrm{C}_{3} \mathrm{H}_{8} \mathrm{NO}\right)$ as an oxidant was investigated. ${ }^{23-25}$ Here, the authors studied the influence of the immobilization strategy, the density and type of Fn subunit on the mineralization process. The mineralized particles were extensively characterized through electron microscopy with the additional investigation of particle sizes, surface charge, circular dichroism (CD) spectra of the adsorbed proteins, crystal phase and magnetic properties.

\section{Experimental section}

\subsection{Materials}

Silica particles (Stöber) were obtained from FO Center Inc., USA (diameter $150 \mathrm{~nm}$, lot number 100625-01). APTES (lot number SHBF3990V, 99\% purity, ABCR GmbH, Germany), TESPSA (lot number 1165003, 95\% purity, ABCR GmbH, Germany), highperformance liquid chromatography-grade toluene (lot number SZBC111SV, $>99 \cdot 7 \%$ purity, Sigma-Aldrich, Germany) and absolute ethanol (lot number 150100530, VWR Chemicals, Germany) were purchased from different suppliers as specified. 2-( $N$-Morpholino) ethanesulfonic acid (MES) buffer (lot number 011M8418), NHS (lot number $\mathrm{BCBD} 1270,>97 \%$ purity), EDC (lot number 040M17411V), imidazole buffer solution (lot number BCBH5414V), trimethylamine $\mathrm{N}$-oxide (lot number $\mathrm{SHBB} 2238 \mathrm{~V}, 98 \%$ purity), ammonium iron (II) sulfate hexahydrate $\left(\left(\mathrm{NH}_{4}\right)_{2} \mathrm{Fe}\left(\mathrm{SO}_{4}\right)_{2}\right.$, lot number HKBK3985V, 99\% purity) and sodium hydroxide $(\mathrm{NaOH}$; lot number $16 \mathrm{C} 100018, \geq 98 \cdot 0 \%$, pellets) were obtained from SigmaAldrich (Germany). Human Fn light chain (full-length protein, lot number GR201643-2, molecular weight $19 \mathrm{kDa}$ ) and human $\mathrm{Fn}$ heavy chain (full-length protein, lot number GR44657-10, molecular weight $21 \mathrm{kDa}$ ) were purchased from Abcam (UK).

All experiments were carried out with double-deionized water $\left(\mathrm{ddH}_{2} \mathrm{O}\right)$ with an $18 \mathrm{~m} \Omega$ resistivity (Synergy Ultrapure Water System Millipore Corp., USA).

\subsection{Material synthesis and functionalization}

The surface of the silica particles was functionalized with amino or carboxyl groups according to Hoffman et al. ${ }^{26}$ and Balas et al. ${ }^{27}$ For this purpose, $1 \mathrm{~g}$ of silica particles was dispersed in a toluene solution containing APTES or TESPSA. The amount of silane required to functionalize the particle surface fully was calculated by considering the specific surface area and surface hydroxyl density of $4.9 \mathrm{OH} / \mathrm{nm}^{2}$, as reported by Nieto et al. ${ }^{28,29}$. The specific surface area was obtained from nitrogen gas $\left(\mathrm{N}_{2}\right)$ adsorption as later described. Prior to silane addition, the reaction system was purged with argon (Ar) for $30 \mathrm{~min}$ to try to remove as much water as possible from the system. A toluene solution was added to the silica particles in which the particles were dispersed by magnetic stirring and the temperature of the reaction was increased to $110^{\circ} \mathrm{C}$. Afterward, silane was added to the mixture to start the reaction and the system was maintained under these conditions for $6 \mathrm{~h}$ and constantly stirred. Particles were filtered and washed once with toluene and twice with absolute ethanol. For each washing step, the suspensions were centrifuged at 5000 revolutions per minute (rpm) for $10 \mathrm{~min}$ (Heraeus Megafuge 16 centrifuge, Thermo Fisher Scientific Inc., USA). Finally, the supernatants were discarded and the functionalized particles were dried at $70^{\circ} \mathrm{C}$ for $12 \mathrm{~h}$.

\subsection{Fn immobilization}

Before immobilization, Fn homopolymer solutions were dialyzed to remove any additional salts from the buffer. Dialysis tubes with a molecular weight cutoff of 8-10 kDa (Spectra/Por Float-A-Lyzer G2, Spectrum Laboratories Inc, the Netherlands) were prepared according to the manufacturer's instructions. The tubes were first soaked in a $10 \mathrm{vol}$. \% ethanol/water solution for $10 \mathrm{~min}$ and then

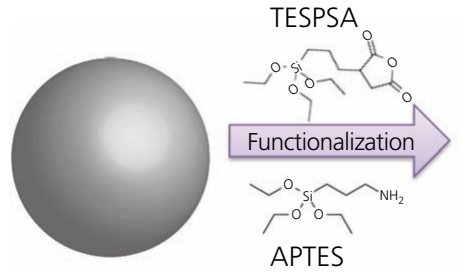

APTES 3-(Aminoprpyl)triethoxysilane TESPSA 3-(Triethoxysilyl)proylsuccinic anhydride
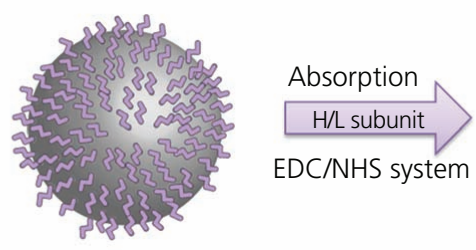

NHS $N$-Hydroxysuccinimide EDC $N$-(3-Dimethylaminopropyl)-N-ethylcarbodiimide

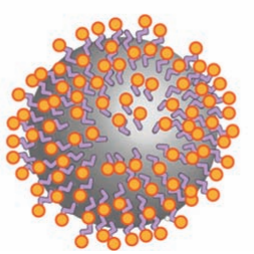

Iron ion source Oxidant

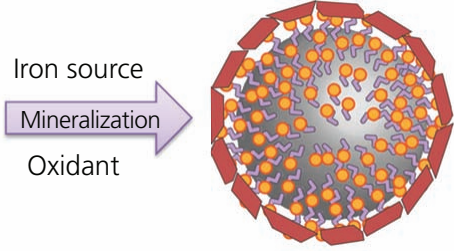

Ferrous ammonium sulfate Trimethylamine $\mathrm{N}$-oxide

Figure 1. Schematic diagram of the functionalization and mineralization process on the basis of silica particles. Two different silanes APTES and TESPSA were used for the surface functionalization. For immobilization of Fn, adsorption and the EDC/NHS linker system were investigated. Mineralization of iron oxide was initiated with the oxidant trimethylamine $\mathrm{N}$-oxide 
immersed in water for $20 \mathrm{~min}$ and rinsed. The tubes were then filled with $1 \mathrm{ml}$ protein solution and dialyzed against $\mathrm{ddH}_{2} \mathrm{O}$ exchanged four times every $30 \mathrm{~min}$.

Two approaches to immobilization were used: physisorption and covalent immobilization with EDC/NHS. For the Fn homopolymers' immobilization by physisorption, ${ }^{22}$ the silanefunctionalized silicon dioxide $\left(\mathrm{SiO}_{2}\right)$ particles were first suspended in MES buffer $(0 \cdot 1 \mathrm{M} \mathrm{pH} 6)$ and ultrasonicated at a frequency of $20 \mathrm{kHz}$ with pulses of $150 \mathrm{~W} / \mathrm{s}$ for $5 \mathrm{~min}$ using an ultrasonicator (Sonifier 450, Branson, USA). Afterward, a solution of the corresponding dialyzed protein with a sufficient concentration (see the online supplementary material) to coat the entire surface of the silica particles (according to the specific surface area calculated by nitrogen gas adsorption) was added and the suspension was kept in $2 \mathrm{ml}$ polypropylene tubes (Safe-Lock microcentrifuge tubes, Eppendorf, Germany) on a vibrating plate (Thermomixer C, Eppendorf, Germany) at $0-4^{\circ} \mathrm{C}$ for $18 \mathrm{~h}$. The particles were recovered and washed once with MES buffer and thrice with $\mathrm{ddH}_{2} \mathrm{O}$ by centrifugation at $10000 \mathrm{rpm}$ for $10 \mathrm{~min}$ at $12^{\circ} \mathrm{C}$ (Heraeus Fresco Centrifuge, Thermo Electron Corporation, USA) in order to remove any unreacted cross-linkers and unbound proteins. The resulting precipitates were dissolved in $1 \mathrm{ml}$ MES buffer, and the samples were stored at $4^{\circ} \mathrm{C}$.

Covalent immobilization was carried out using EDC/NHS. ${ }^{19-21}$ Silanized silicon dioxide particles were suspended in MES buffer $(0.1 \mathrm{M}, \mathrm{pH} 6)$ as previously described, and the cross-linkers were added in molar ratios of 10:1 (NHS:Fn) and 5:1 (EDC:NHS). The protein solution, prepared in the same way as previously mentioned, was then added to the suspension and placed on a vibrating plate at $4^{\circ} \mathrm{C}$ for $3 \mathrm{~h}$. The particles were recovered and washed once with MES buffer and thrice with $\mathrm{ddH}_{2} \mathrm{O}$ by centrifugation in the same way as described previously for the immobilization by physisorption. The precipitates were dissolved in $1 \mathrm{ml}$ of MES buffer and stored at $4^{\circ} \mathrm{C}$.

\subsection{Circular dichroism}

CD spectra of the immobilized Fn homopolymers were recorded with an Applied Photophysics Chirascan spectrometer running the Pro-Data Chirascan software (version 4.2.22). Three repeat scans for each sample were measured at $25^{\circ} \mathrm{C}$ over the wavelength range $250-180 \mathrm{~nm}$ with an interval of $1 \mathrm{~nm}$ using a Suprasil quartz cell (Hellma UK Ltd) with a path length of $1 \mathrm{~cm}$. CD measurements of the differently modified nanoparticles were measured under the same conditions. For each of the triplicate measurements of the immobilized Fn, the baseline of the corresponding nanoparticle measurement was subtracted and the net spectrum smoothed with a Savitsky-Golay filter using a smoothing window of five data points. The mean residue ellipticity $\theta_{\text {MRE }}$ was calculated using ${ }^{30}$

1. $\theta_{\mathrm{MRE}}=\frac{\theta_{\mathrm{mdeg}}}{c l n}$ where $\theta_{\text {mdeg }}$ is the raw measured CD signal in millidegrees, $n$ corresponds to the number of amino acids of the Fn protein, $l$ is the path length of the quartz cuvette and $c$ is the molar concentration of the peptide. Approximations of the protein concentrations were determined using ultraviolet absorbance at 205 and $214 \mathrm{~nm}^{31,32}$ Analysis of the measured CD spectra regarding the secondary structural components has been performed through the Beta Structure Selection (BeStSel) web server. ${ }^{33}$ In case of a poor signal-to-noise ratio of the CD spectra, the BeStSel server has been used to rescale the spectra using the so-called best factor. ${ }^{33}$

\subsection{Iron oxide mineralization}

After immobilization of the Fn, the growth of iron oxide crystals on the silicon dioxide particle surfaces was initiated at the immobilized proteins as nucleation sites. The mineralization reaction was carried out at anaerobic conditions ${ }^{24}$ in successive mineralization steps by increasing the iron ion concentration in the solution at every step to study how the crystals are growing progressively in size and/or number. Mineralization was carried out using a protocol adapted from Meldrum et al. ${ }^{23,25}$ and Wong et $a .^{24}$ which was established for the mineralization of apo-Fn. First, the silicon dioxide particles functionalized with Fn were resuspended in imidazol buffer $(20 \mathrm{mM}, \mathrm{pH} 8.5)$ and bubbled with nitrogen gas for $1 \mathrm{~h}$. The $\mathrm{pH}$ was titrated to 8.5 with $1 \mathrm{M}$ sodium hydroxide, and the mixture was stirred at $65^{\circ} \mathrm{C}$, maintaining the inert atmosphere. Simultaneously, aqueous solutions of trimethylamine $N$-oxide $(0 \cdot 1 \mathrm{M})$ and ammonium iron (II) sulfate hexahydrate $\left(\left(\mathrm{NH}_{4}\right)_{2} \mathrm{Fe}\left(\mathrm{SO}_{4}\right)_{2}, 0 \cdot 08 \mathrm{M}\right)$, which were used as oxidant and iron source, respectively, were prepared and deaerated with argon for $30 \mathrm{~min}$ before use. $\left(\mathrm{NH}_{4}\right) \mathrm{Fe}\left(\mathrm{SO}_{4}\right)_{2}$ solution $(0 \cdot 15 \mathrm{ml})$ was added to the particle suspension, and after 15 min under stirring at the same initial conditions, a second aliquot of $0 \cdot 15 \mathrm{ml}\left(\mathrm{NH}_{4}\right)_{2} \mathrm{Fe}\left(\mathrm{SO}_{4}\right)_{2}$ solution along with $0 \cdot 15 \mathrm{ml}$ of the trimethylamine $\mathrm{N}$-oxide solution as an oxidant was added. This last addition is repeated every 15 min eight times (referred to as steps throughout the text) up to a total of $1.35 \mathrm{ml}$ addition of $\left(\mathrm{NH}_{4}\right)_{2} \mathrm{Fe}\left(\mathrm{SO}_{4}\right)_{2}$, after which the particles were recovered and washed thrice with $\mathrm{ddH}_{2} \mathrm{O}$ water by centrifugation at $5000 \mathrm{rpm}$ for $15 \mathrm{~min}$. Samples were taken after the first $(0.3 \mathrm{ml}$ $\left(\mathrm{NH}_{4}\right)_{2} \mathrm{Fe}\left(\mathrm{SO}_{4}\right)_{2}$ solution $/ 0 \cdot 15 \mathrm{ml}$ trimethylamine $N$-oxide solution added), the fourth $\left(0.75 \mathrm{ml}\left(\mathrm{NH}_{4}\right)_{2} \mathrm{Fe}\left(\mathrm{SO}_{4}\right)_{2}\right.$ solution $/ 0.6 \mathrm{ml}$ trimethylamine $\mathrm{N}$-oxide solution added) and the eight mineralization step $\left(1.35 \mathrm{ml} \quad\left(\mathrm{NH}_{4}\right)_{2} \mathrm{Fe}\left(\mathrm{SO}_{4}\right)_{2} \quad\right.$ solution/1.2 ml trimethylamine $\mathrm{N}$-oxide solution added). With each increase in iron concentration at each mineralization step, a more and more intense solution coloration was observed due to the formation of iron complexes in solution (Figure S8 in the online supplementary material), an effect which to a similar extend can also be observed on samples with both physisorbed and covalently immobilized Fn.

\subsection{Dynamic light scattering}

Particle size and $\zeta$-potential were determined by dynamic light scattering (DLS) using a Zetasizer nano-ZSP equipped with a 
multipurpose titrator (Malvern, UK) using disposable folded capillary cells. All measurements were conducted with $5 \mathrm{mg} / \mathrm{ml}$ silicon dioxide nanoparticle suspensions in $\mathrm{ddH}_{2} \mathrm{O}$.

\subsection{Electron microscopy}

For the morphological characterization, transmission electron microscopy (TEM), scanning transmission microscopy (STEM), energy-dispersive X-ray (EDX) analysis and selected area electron diffraction (SAED) were carried out using a Titan 80-300 ST microscope (FEI, the Netherlands) with a $300 \mathrm{keV}$ electron beam accelerating voltage and a $1.3 \times 10^{-7}$ mbar vacuum, using a corrector for the imaging lens. For analysis, the powder samples were prepared in ethanol or water and sonicated for $2 \mathrm{~min}$. A drop of this mixture was placed on 200-mesh copper grids covered with a Formvar film (S162, Plano GmbH, Germany) and then dried before analysis. SEM analysis was conducted with a CamScan Series 2 device (Applied Beams, Oregon, USA). The samples were placed on double-sided carbon adhesive tape, mounted on a sample holder and sputtered with a thin gold layer (Emitech K550, Judges Scientific, UK).

Compositional analysis was carried out by EDX (EDX detecting unit PV9723/10 built in the TEM microscope). The spectra data were evaluated with the TIA software from FEI.

\subsection{Magnetic characterization}

The magnetic characterization was performed by using a superconducting quantum interference device (SQUID) on an MPMS XL-5 magnetometer (Quantum Design). $M(H)$ loops were recorded in hysteresis mode from 50 to $-50 \mathrm{kOe} . M(H)$ loops at $5 \mathrm{~K}$ were recorded in $2 \mathrm{kOe}$ increments from 50 to $4 \mathrm{kOe}$, in $500 \mathrm{Oe}$ increments from 4 to $-6 \mathrm{kOe}$ and again in $2 \mathrm{kOe}$ steps from -6 to $-50 \mathrm{kOe} . M(H)$ loops at $293 \mathrm{~K}$ were recorded in $2 \mathrm{kOe}$ increments from $( \pm) 50$ to $( \pm) 4 \mathrm{kOe}$ and in $250 \mathrm{Oe}$ increments from 3 to -3 kOe. $M(T)$ zero-field-cooled (ZFC)/field-cooled curves were recorded in $5 \mathrm{~K}$ increments at a heating/cooling rate of $5 \mathrm{~K} / \mathrm{min}$.

\subsection{Molecular dynamics simulations}

The structures of $\mathrm{L}$ and $\mathrm{H}$ subunits of Fn used in the simulations were taken from the Research Collaboratory for Structural Bioinformatics Protein Data Bank (PDB) (PDB IDs 2FG8 and 2FHA, respectively). Residues $1-5$ in the $\mathrm{H}$ subunit of Fn which are not present in the X-ray structure were added by using the Leap program of the AmberTools package. The $\mathrm{H}++$ web server tool described by Anandakrishnan et al. ${ }^{34}$ Myers et al. ${ }^{35}$ and Gordon et $a l^{36}$ was used to adjust the protonation state of the titratable amino acids according to the $\mathrm{pH}$ values of 3 and 8 . The total net charges of the $\mathrm{L}$ subunit were $21 \mathrm{e}$ at $\mathrm{pH} 3$ and $-6 \mathrm{e}$ at $\mathrm{pH} 8$, and those for the $\mathrm{H}$ subunit were $16 \mathrm{e}$ at $\mathrm{pH} 3$ and $-10 \mathrm{e}$ at $\mathrm{pH} 8$. The amorphous silica surface with a slab size of $28 \times 28 \mathrm{~nm}^{2}$ is taken from the previous work of Cole et al. ${ }^{37}$ whereby the protonation state of the surface terminal groups at the different $\mathrm{pH}$ values was set to reproduce the average values of potentiometric titration experiments, ${ }^{38-41}$ resulting in final surface charge densities of $0 \cdot 0$ and $-0.07 \mathrm{~cm}^{-2}$ at $\mathrm{pH} 3 \cdot 0$ and $8 \cdot 0$, respectively.
All calculations were performed with the Amber program package. $^{42}$ The static single-point calculations were performed without periodic boundary conditions in an implicit-solvent model based on the Onufriev-Bashford-Case generalized Born model, with the Born radii described by Onufriev et al. ${ }^{43}$ The non bonded interactions within a cutoff distance of $100 \mathrm{~nm}$ are described by the Amber-99SB force field parameter set for the protein in combination with the parameter set for silica/water/ protein interfaces described by Butenuth et al. ${ }^{44}$ The static singlepoint calculations of the protein were performed at protein-surface heights of $0-50 \AA$, in $2 \AA$ steps. The protein-surface height is defined as the distance between the highest atom of the surface and the lowest atom of the protein in the direction perpendicular to the surface slab. For every height, the protein is rotated around its geometrical center in $60^{\circ}$ steps around the $x$ - and $y$-axes, resulting in 36 different orientations per height step.

In order to estimate more precisely the preferential protein orientation, the protein is placed at a height of $12 \AA$ above the surface and rotated around its geometrical center in $5^{\circ}$ steps around the $x$ - and $y$-axes.

The all-atom molecular dynamics (MD) simulations were performed in explicit water under periodic boundary conditions. The subunits were initially placed at a height of $12 \AA$ above the surface, in orientations in which the inner or outer sides pointed to the surface. The simulations were performed in the NVT ensemble at $300 \mathrm{~K}$, with a protonation state of the surface and the protein corresponding to $\mathrm{pH} 3$ and $\mathrm{pH} 8$. The resulting (negative) net charge of the simulation cell is compensated for by adding an equal amount of sodium $\left(\mathrm{Na}^{+}\right)$ions in the water-filled cells. The particle mesh Ewald method of treating electrostatic interactions and a time step of $1 \mathrm{fs}$ were used. All surface atoms except the terminal $\mathrm{OH}$ groups were constrained in their equilibrium position. The visualization and analysis of the MD trajectories were performed with VMD. ${ }^{45}$

\section{Results and discussion}

\subsection{Computer simulations}

In order to assess the feasibility of the adsorption of Fn on a silicon dioxide surface while retaining the activity for iron oxide mineralization, atomistic simulations were first performed to estimate the driving forces toward the non covalent adsorption of Fn subunits to the amorphous silicon dioxide surface. These simulations were performed in implicit solvent at the level of the Derjaguin-Landau-Verwey-Overbeek theory following the procedure of a previous work. ${ }^{46}$ This allowed predicting the putative preferential protein orientation for initial adsorption at a given $\mathrm{pH}$ and provided an assessment of the strength of the surface-protein interactions prior to adsorption. Although the scope of the simulation is limited to individual, unassembled Fn subunits, the preferred orientation of the inward-facing sides of subunits in Fn cages could hint at the denaturation of Fn cages during adsorption. 
The forces of static single-point calculations for all heights and orientations are displayed on the left-hand side in Figure 2 for the $\mathrm{H}$ subunit (Figure 2(a)) and the L subunit (Figure 2(b)) for $\mathrm{pH} 3$ and 8 , respectively. The colored semitransparent areas symbolize the standard deviations for all resulting profiles at the given $\mathrm{pH}$. Negative force values represent attractive forces onto the protein, with the zero-energy point set to the average value at the maximum distance of $50 \AA$. At pH 3, the surface is almost neutral and only attractive interactions can be observed for $\mathrm{H}$ and $\mathrm{L}$ subunits. At $\mathrm{pH} 8$, the silica surface is negatively charged and the interaction forces are either attractive or repulsive depending on the specific orientation of the subunit due to the occurrence of negatively or positively charged residues at the surface of the respective subunit.

The computed relative energies for each protein orientation at a height of $12 \AA$ above the surface is displayed as $2 \mathrm{D}$ color maps for $\mathrm{H}$ and $\mathrm{L}$ subunits and each $\mathrm{pH}$ on the right-hand side in Figure 2. The average interaction energy is set to zero (white), and the changes of the relative energy varied between $-1.6 \mathrm{eV}$ (green) for attractive interactions and $+1.6 \mathrm{eV}$ (red) for repulsive interactions. For $\mathrm{pH} \mathrm{3,} \mathrm{the} \mathrm{color} \mathrm{maps} \mathrm{for} \mathrm{the} \mathrm{H}$ (Figure 2(c)) and L (Figure 2(e)) subunits present only attractive interactions between the silica surface and all orientations of the protein. The color maps for the H (Figure 2(d)) and L (Figure 2(f)) subunits at $\mathrm{pH} 8$ generally show the same result. Thus, the rotation around the $y$-axis between 0 and $180^{\circ}$ is energetically favorable in

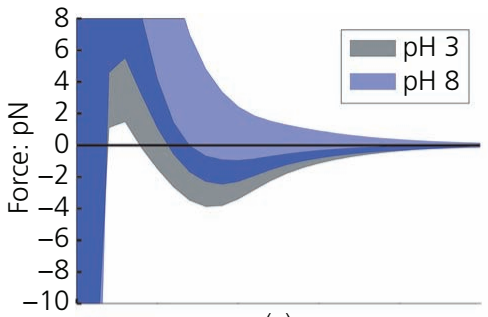

(a)

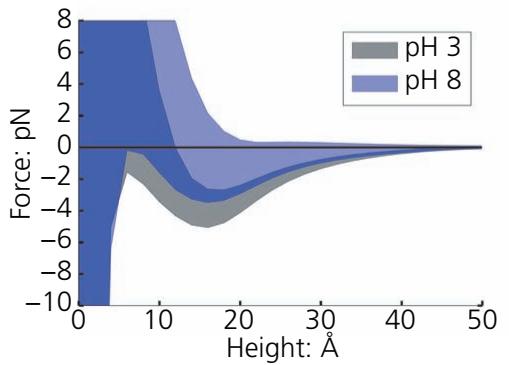

(b)

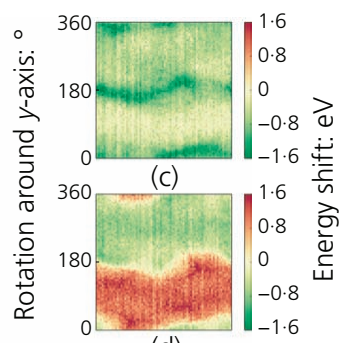

(d)

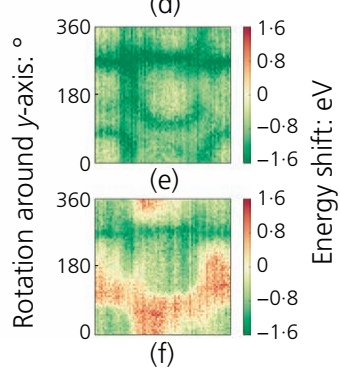

Rotation around $x$-axis: ${ }^{\circ}$
Figure 2. Interaction forces between (a) $H$ and (b) L Fn subunits with an amorphous silicon dioxide surface model calculated for all possible protein orientations at two $\mathrm{pH}$ values (3 and 8). The colored semitransparent areas are the standard deviations obtained from rotating the protein around the $x$ - and $y$-axes. The zero-energy point is set to the average value at the maximum distance of $50 \AA$. The interaction energies between the silica surface and proteins which are rotated at a height of $12 \AA$ reported as color maps on the right, for the cases (c) $\mathrm{H}, \mathrm{pH} 3$; (d) $\mathrm{H}, \mathrm{pH}$ 8; (e) L, pH 3; and (f) L, pH 8 contrast to rotations around the $y$-axis between 180 and $360^{\circ}$. For rotations around the $y$-axis between 0 and $180^{\circ}$, the outer side of the protein - that is, the surface which is located at the outside of the whole Fn protein shell - faces toward the silica surface. Accordingly, it can be concluded that the simulations show that there is a favorable interaction for the non covalent anchoring of Fn subunits at $\mathrm{pH} 8$ in which the inner side of the protein, which is responsible for its mineralization activity, points away from the silica surface and becomes available for biomineralization while potentially maintaining the integrity of assembled Fn cages.

Subsequently, all-atom MD simulations in explicit water solvent are performed to verify whether actual anchoring of the protein to the surface takes place in the orientation predicted by the implicitsolvent calculations. Figure 3 summarizes the results for one $\mathrm{H}$ subunit at $\mathrm{pH} 8$, with the inner (top) and outer (bottom) side pointing to the surface as the initial configuration. Snapshots of the initial configuration (left), after $15 \mathrm{~ns}$ (middle) and after $30 \mathrm{~ns}$ (right) are shown. The images displayed in Figure 3 are representative of the results observed in all other simulations. The simulations predict that anchoring to the surface takes place after rotation of the units from a side-on to an end-on configuration and with formation of only a few unstable surface contacts, irrespective of the $\mathrm{pH}$. In fact, as will be shown later, physisorption experiments led to unstably bound proteins, which were washed off the surface during mineralization. This behavior can be explained by the small attractive force between Fn subunits and silica, which are about $-5 \mathrm{pN}$ or less. In comparison, in the paper of Hildebrand et al. ${ }^{46}$ much larger attractive forces of magnitude ranging between -20 and $-60 \mathrm{pN}$ have been predicted to act between chymotrypsin or lysozyme and silica surfaces.

\subsection{Immobilization experiments}

Based on the tentative predictions of the simulation experiments, the authors investigated the immobilization of $\mathrm{H}$ and $\mathrm{L}$ homopolymers through both physisorption and covalent immobilization experimentally. Before and after every stage of the
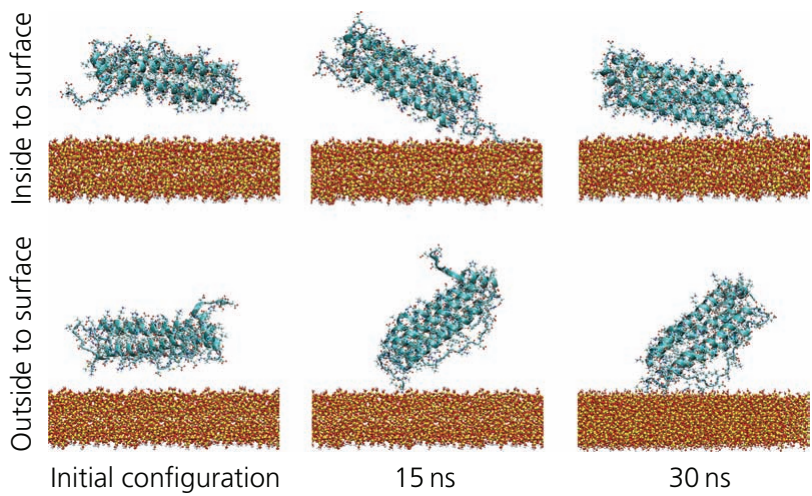

Figure 3. Free-fall simulations of the $\mathrm{Fn} \mathrm{H}$ subunit at $\mathrm{pH} 8$ with the inner (top) and outer (bottom) side pointing to the surface at the initial configuration. Snapshots of the initial configuration (left), after $15 \mathrm{~ns}$ (middle) and after $30 \mathrm{~ns}$ (right) 
Bioinspired, Biomimetic and Nanobiomaterials Volume 8 Issue BBN1
Mineralization of iron oxide by ferritin homopolymers immobilized on $\mathrm{SiO}_{2}$ nanoparticles

Carmona, Treccani, Michaelis et al. process, the particles were characterized by DLS and TEM. In order to differentiate better between the different stages of the authors' approach, the chemical modification of the silica surface with silanes is referred to as functionalization, while the adsorption of protein is referred to as immobilization. As can be seen in Figure 4 (more images of other samples can be found in Figure S1 in the online supplementary material), the TEM images of the particles show a similar particle size and a spherical morphology before and after functionalization and protein immobilization. Silane molecules that react with $\mathrm{OH}$ groups which are naturally present on the silicon dioxide particle surface, the cross-linker and $\mathrm{H}-$ and L-Fn are not directly visible in the TEM images. The hydrodynamic diameter of the particles, as determined by DLS (size distribution weighted by numbers (Table 1)) shows a slight increase in particle size upon protein adsorption onto the unfunctionalized particles. A similar increase in size can be observed after silanization with APTES and TESPSA. Immobilization of Fn on the TESPSA-functionalized particles does not significantly change the observed particle diameter any further, while a slight increase in size was noticeable with Fn immobilized on APTES. However, polydispersity (as observed in the polydispersity index (PDI); Table 1) is somewhat increased for dispersions with Fn immobilized on silane-functionalized surfaces, particularly for the samples with Fn covalently bound to the
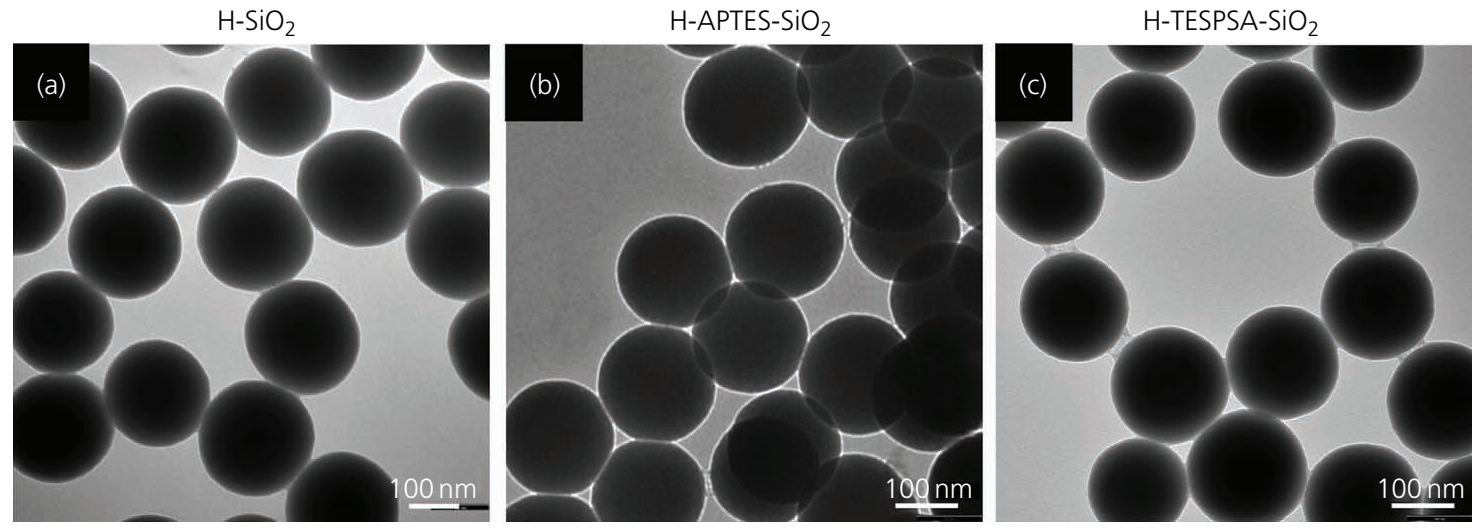

Figure 4. TEM images of the silica nanoparticles $(150 \mathrm{~nm})$ with $\mathrm{H}$-Fn immobilized by physisorption using different surface functionalizations: (a) bare; (b) APTES; (c) TESPSA

Table 1. Overview of the investigated samples including DLS data

\begin{tabular}{|c|c|c|c|c|c|}
\hline Sample name & $\begin{array}{l}\text { Immobilization } \\
\text { type }\end{array}$ & Description & $\begin{array}{c}\text { Zeta } \\
\text { potential: } \\
\text { mV }\end{array}$ & $\begin{array}{l}\text { DLS size (weighted } \\
\text { by number): } \mathrm{nm}\end{array}$ & PDI \\
\hline $\mathrm{SiO}_{2}$ & & & $-39 \cdot 8$ & $190 \cdot 2$ & $0 \cdot 11$ \\
\hline $\mathrm{H}-\mathrm{SiO}_{2}$ & Physisorption & $\begin{array}{l}\text { H-Fn immobilized by physisorption on untreated silicon } \\
\text { dioxide particles }\end{array}$ & $-37 \cdot 1$ & $198 \cdot 0$ & 0.06 \\
\hline $\mathrm{L}-\mathrm{SiO}_{2}$ & Physisorption & $\begin{array}{l}\text { L-Fn immobilized by physisorption on untreated silicon } \\
\text { dioxide particles }\end{array}$ & $-38 \cdot 5$ & $195 \cdot 4$ & $0 \cdot 1$ \\
\hline APTES-SiO 2 & & APTES-silanized silicon dioxide particles & $4 \cdot 1$ & $196 \cdot 6$ & $0 \cdot 1$ \\
\hline $\mathrm{TESPSA}_{-\mathrm{SiO}_{2}}$ & & TESPSA-silanized silicon dioxide particles & $-37 \cdot 8$ & $196 \cdot 0$ & $0 \cdot 12$ \\
\hline $\mathrm{H}$-APTES-SiO 2 & Physisorption & $\begin{array}{l}\text { H-Fn immobilized by physisorption on APTES-silanized } \\
\text { silicon dioxide particles }\end{array}$ & $-28 \cdot 8$ & $204 \cdot 7$ & $0 \cdot 34$ \\
\hline L-APTES-SiO ${ }_{2}$ & Physisorption & $\begin{array}{l}\text { L-Fn immobilized by physisorption on APTES-silanized } \\
\text { silicon dioxide particles }\end{array}$ & $-23 \cdot 1$ & $199 \cdot 8$ & $0 \cdot 14$ \\
\hline $\mathrm{H}$-TESPSA-SiO 2 & Physisorption & $\begin{array}{l}\text { H-Fn immobilized by physisorption on TESPSA-silanized } \\
\text { silicon dioxide particles }\end{array}$ & $-36 \cdot 5$ & $193 \cdot 1$ & 0.22 \\
\hline L-TESPSA-SiO 2 & Physisorption & $\begin{array}{l}\text { L-Fn immobilized by physisorption on TESPSA-silanized } \\
\text { silicon dioxide particles }\end{array}$ & $-37 \cdot 4$ & $197 \cdot 3$ & $0 \cdot 11$ \\
\hline $\mathrm{H}$-Cov-APTES-SiO 2 & $\begin{array}{l}\text { Covalent } \\
\text { immobilization }\end{array}$ & $\begin{array}{l}\text { H-Fn immobilized by covalent binding with EDC/NHS on } \\
\text { APTES-silanized silicon dioxide particles }\end{array}$ & $-24 \cdot 4$ & $235 \cdot 5$ & $0 \cdot 24$ \\
\hline L-Cov-APTES-SiO 2 & $\begin{array}{l}\text { Covalent } \\
\text { immobilization }\end{array}$ & $\begin{array}{l}\text { L-Fn immobilized by covalent binding with EDC/NHS on } \\
\text { APTES-silanized silicon dioxide particles }\end{array}$ & $-34 \cdot 6$ & $217 \cdot 0$ & $0 \cdot 29$ \\
\hline H-Cov-TESPSA-SiO ${ }_{2}$ & $\begin{array}{l}\text { Covalent } \\
\text { immobilization }\end{array}$ & $\begin{array}{l}\text { H-Fn immobilized by covalent binding with EDC/NHS on } \\
\text { TESPSA-silanized silicon dioxide particles }\end{array}$ & $-39 \cdot 0$ & $194 \cdot 5$ & 0.05 \\
\hline L-Cov-TESPSA-SiO 2 & $\begin{array}{l}\text { Covalent } \\
\text { immobilization }\end{array}$ & $\begin{array}{l}\text { L-Fn immobilized by covalent binding with EDC/NHS on } \\
\text { TESPSA-silanized silicon dioxide particles }\end{array}$ & $-39 \cdot 8$ & $199 \cdot 5$ & $0 \cdot 1$ \\
\hline
\end{tabular}


APTES-covered surface (H-Cov-APTES-SiO ${ }_{2}$ and L-Cov-APTES$\mathrm{SiO}_{2}$, Table 1). For these two samples, the increased size could be explained by aggregation rather than an increase in particle diameter. In some cases, a small accumulation of the material in larger artifacts after protein immobilization could be visible as a thin film between particles in the dried TEM samples (Figures 4(b) and $4(\mathrm{c}))$, which points into the same direction.

The influence of the immobilization process on the secondary structure of the Fn proteins was exemplarily investigated through CD spectroscopy for H-Fn. The results are summarized in Figure 5. The gray shade represents the deviation in the $\mathrm{CD}$ measurements around an average of each data point, while the colored line represent the fitted spectrum from the BeStSel web server. ${ }^{33}$ The overlap of measurements and predictions is quite good; the highest deviations can be found for the adsorbed spectrum on nanoparticles with physisorbed proteins $\left(\mathrm{H}-\mathrm{SiO}_{2}\right.$, Figure 5(b)). Note, however, that the necessary rescaling of the raw data due to the accessible concentrations and potential scattering effects also slightly influences the analysis regarding the conformational contributions. The CD spectra of H-Fn in solution (Figure 5(a)) is characterized by two minima at around 222 and around $210 \mathrm{~nm}$, respectively, as well as an intense maximum around $195 \mathrm{~nm}$. According to the BeStSel analysis, H-Fn features an overall helicity of around 30\%. The full secondary structure analysis of all spectra can be obtained in Table S1 in the online supplementary material. While in comparison to the CD spectra of H-Fn in solution all adsorbed spectra (Figures 5(b)-5(d)) agree in an intensity increase at around $210 \mathrm{~nm}$, they differ in the analysis of the contribution of structural components obtained through BeStSel. One common development for the adsorbed spectra is the decrease of the helicity to values around $<11 \%$. While the direct comparison of the CD spectra suggests that the structural changes are independent of the surface modifications, the analysis of the secondary structural components reveals differences (Figures 5(b)-5(d) and Table S1 in the online supplementary material). The covalent attachment of H-Fn to APTES- and TESPSA-modified silica particles reveals only slight differences in terms of the secondary structure components. As will be discussed later, the observed structural changes do not seem to impede the mineralization activity of the homopolymers.

\subsection{Mineralization}

After the immobilization of Fn, its ability to induce iron oxide nucleation and growth through a stepwise mineralization procedure after Meldrum et $a l^{23,25}$ and Wong et al. ${ }^{24}$ was investigated with all samples as listed in Table 1. All samples were analyzed after the first, fourth and eighth stepwise addition of the iron salt $(0.15 \mathrm{ml}$ of $\left.0.08 \mathrm{M}\left(\mathrm{NH}_{4}\right)_{2} \mathrm{Fe}\left(\mathrm{SO}_{4}\right)_{2}\right)$ solution along with the oxidizing agent $(0 \cdot 15 \mathrm{ml}$ of $0 \cdot 1 \mathrm{M}$ trimethylamine $\mathrm{N}$-oxide) solution, as described in Section 2. The addition of the iron ion solution and the oxidant was expected to cause the formation of iron oxide crystallites inside the Fn proteins immobilized on the silica particles. The simulation experiments provided a tentative theoretical assessment about the forces involved in an immobilization by non covalent adsorption. In order to test whether these forces are sufficient to retain the proteins on the surface of the particle during mineralization, the authors compared the bare and functionalized silica particles with protein immobilized by physisorption (Figure 6) or by EDC/NHS (Figure 7).

On non silanized particles with physisorbed $\mathrm{Fn}\left(\mathrm{H}-\mathrm{SiO}_{2}\right.$ or $\left.\mathrm{L}-\mathrm{SiO}_{2}\right)$, no iron oxide nucleation was observed after the first step (Figure 6(b)). Only after the fourth and eighth mineralization steps did irregular crystals nucleate on the particles (Figures 6(c) and 6(d)). The formation of iron oxide nuclei could be identified on the particle surfaces as dark gray dots in the TEM images. The lack of iron oxide formation on the particles is probably related to the low binding affinity of the subunits to the silica surface as suggested in the simulations. Immobilization by physisorption seems indeed to be too weak to maintain adsorption during the mineralization process. Note that homogeneous nucleation of iron oxide in the volume phase of the particle dispersion was not detected during the mineralization procedure with DLS. Accordingly, the observed nucleation events are most likely heterogeneous nucleation at the particle interface.

In contrast to bare silica particles, on silanized particles with physisorbed Fn (H-APTES-SiO 2 , L-APTES-SiO 2 , H-TESPSA-SiO L-TESPSA- $\mathrm{SiO}_{2}$ ), the authors observed the formation of non homogenously distributed iron oxide agglomerates. The presence of these aggregates is visible after four mineralization steps in those cases (Figures 6(f) and 6(h)). The zeta-potential difference of

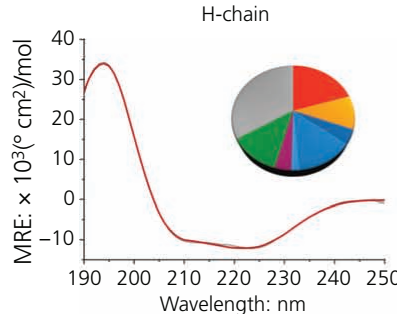

(a)
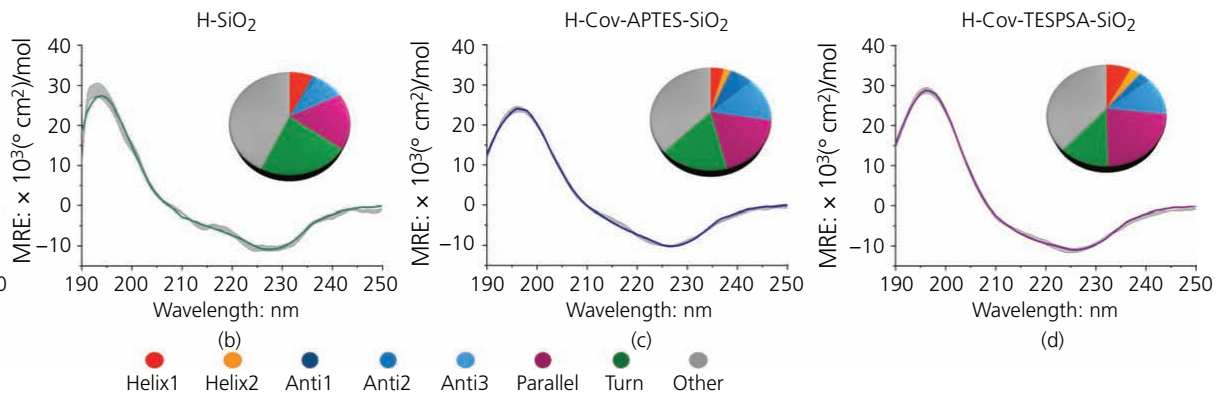

(d)

Figure 5. CD spectra of (a) the H-chain in solution and (b-d) adsorbed/covalently bound to different surface modifications of the silica nanoparticles. The corresponding pie chart of every subfigure summarizes the secondary structure components obtained by the analysis of the spectra using BeStSel. ${ }^{33}$ MRE, mean residue ellipticity 
Bioinspired, Biomimetic and Nanobiomaterials Volume 8 Issue BBN1
Mineralization of iron oxide by ferritin homopolymers immobilized on $\mathrm{SiO}_{2}$

nanoparticles

Carmona, Treccani, Michaelis et al.
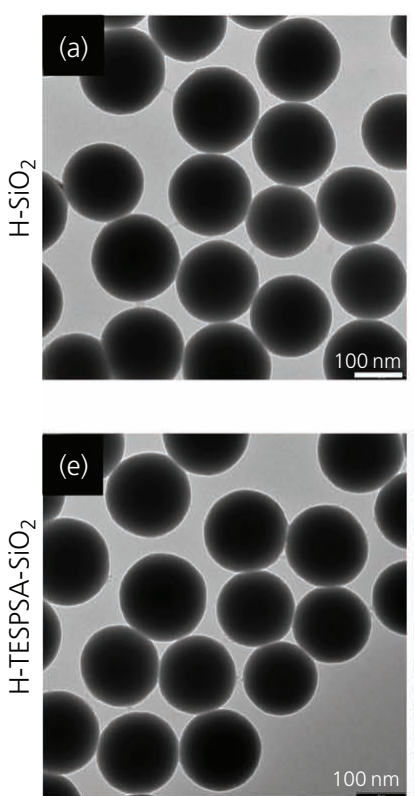

Step 1

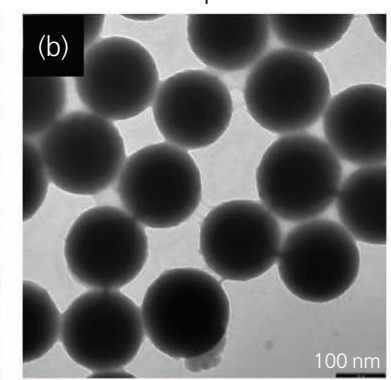

Step 4

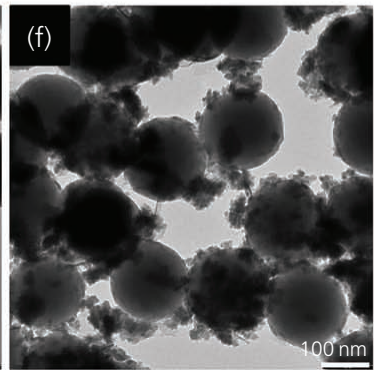

Step 4

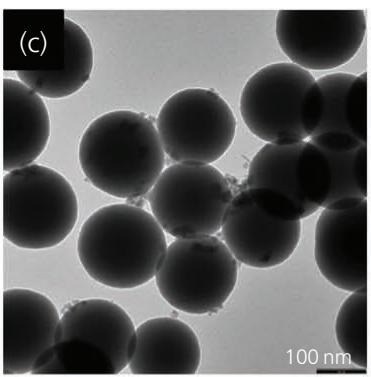

(g)

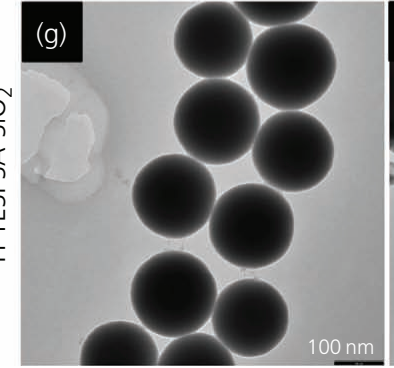

Step 8

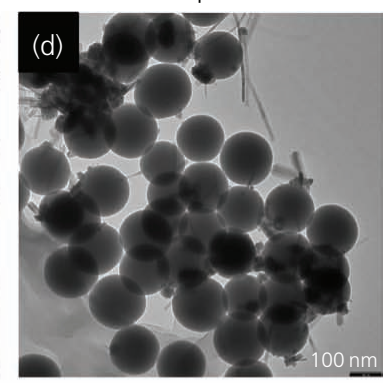

Step 4

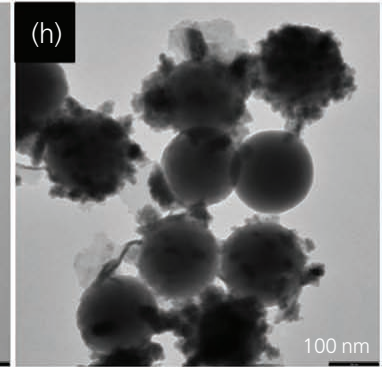

Figure 6. Silicon dioxide particles with $\mathrm{H}-\mathrm{Fn}$ immobilized by physisorption: $\mathrm{H}-\mathrm{SiO}_{2}$ (a) before and after (b) one cycle, (c) four cycles and (d) eight cycles of the mineralization protocol; (e, f) H-TESPSA-SiO 2 and $(g, h) \mathrm{H}_{2}$-APTES-SiO $2(e, g)$ before and $(f, h)$ after four cycles of mineralization protocol

Step 1
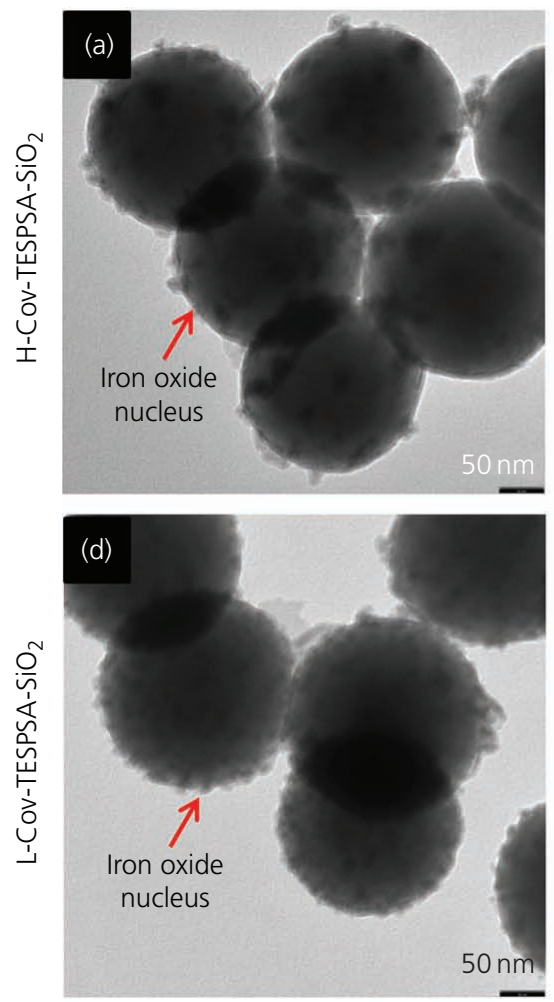

Step 4
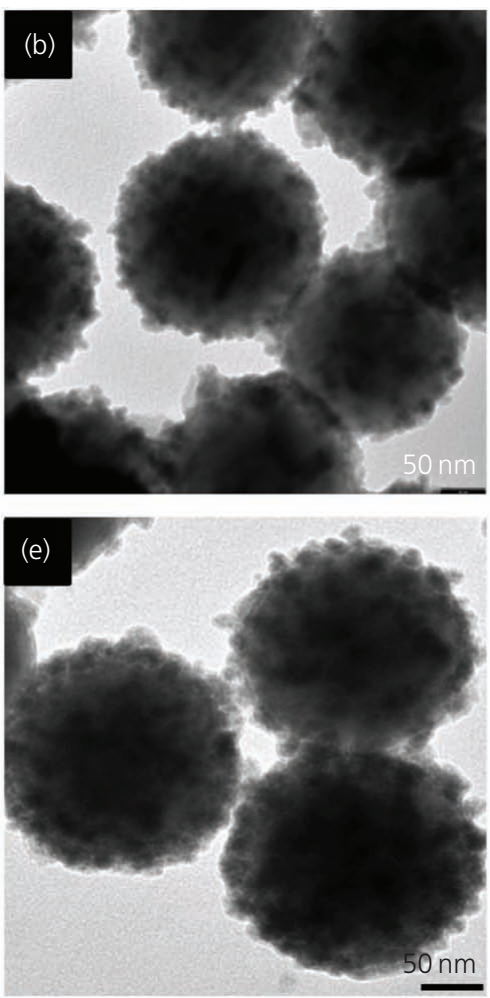

Step 8
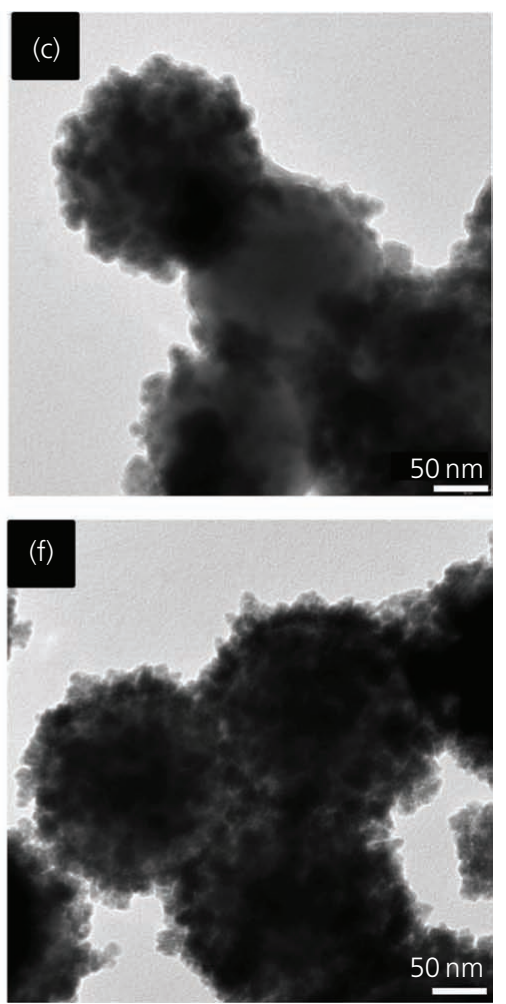

Figure 7. (a-c) H-Cov-TESPSA-SiO 2 and ( $d-f)$ L-Cov-TESPSA- $\mathrm{SiO}_{2}$ in different moments of the mineralization protocol. The TEM images show the samples after $(a, d)$ one cycle, $(b, e)$ four cycles and $(c, f)$ eight cycles of mineralization to observe how the iron oxide film is formed in relation to the added iron salt 
Bioinspired, Biomimetic and Nanobiomaterials Volume 8 Issue BBN1
Mineralization of iron oxide by ferritin homopolymers immobilized on $\mathrm{SiO}_{2}$ nanoparticles

Carmona, Treccani, Michaelis et al. the particles after functionalization with the two silanes (Table 1) may be responsible for a stronger adsorption of Fn, which led to a somewhat controlled mineralization of the silica surface. No differences could be observed between $\mathrm{H}$ and $\mathrm{L}$ homopolymers.

The effect of APTES and TESPSA on mineral formation in silica particles after functionalization without proteins was also examined in control experiments, and no mineral formation was observed at the first mineralization step. Only after the fourth step did irregular crystals form on the particles (Figure S2 in the online supplementary material).

A different mineralization behavior was observed with covalently bound Fn by EDC/NHS cross-linker on APTES- or TESPSAfunctionalized silicon dioxide, namely, H-Cov-APTES-SiO ${ }_{2}$, L-Cov-APTES-SiO ${ }_{2}$, H-Cov-TESPSA-SiO ${ }_{2}$ and L-Cov-TESPSA-SiO (Figure 7; a larger selection of images is shown in Figures $\mathrm{S} 3$ and S4 in the online supplementary material). The number and size of iron oxide nuclei increased with the stepwise addition of iron salt and oxidant and eventually covered the whole particle surface (Figure 7). After every mineralization step, the nuclei are growing as a result of the increased iron ion concentration in the solution. No adventitious mineralization was detected in this case as observed in the notable lack of irregular crystallites. However, no discernible difference could be detected between the mineralization behaviors of L-Fn and H-Fn.

The composition of the iron oxide crystallites was examined using EDX analysis in high-resolution TEM (HR-TEM) in scanning mode combined with SAED. The EDX analysis of the STEMvisualized samples shows a characteristic iron peak. The other detected peaks belong to elements from the grid used as support for the TEM characterization and silicon from the silicon dioxide particles (Figure S5 and Table S2 in the online supplementary material). SAED spectra of the crystallites revealed $d$-spacings fitting for both magnetite and maghemite (Figure S6 in the online supplementary material), which are known to coexist, particularly considering that magnetite rapidly oxidizes into maghemite when exposed to oxygen. ${ }^{47}$

Finally, the magnetic properties of the samples were analyzed (Figure 8). All successfully mineralized particles in which Fn was

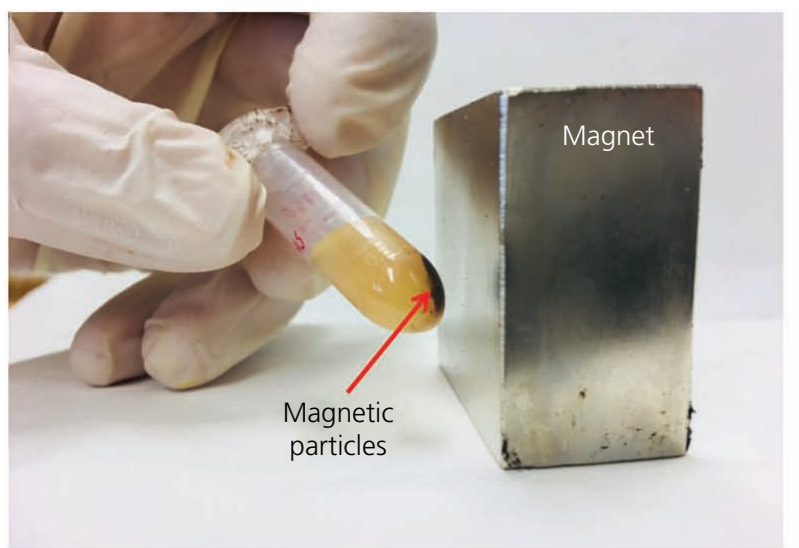

(a)

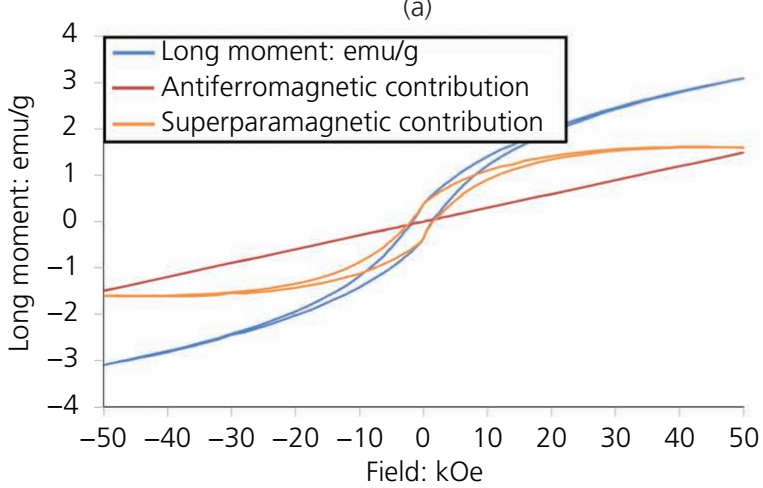

(c)

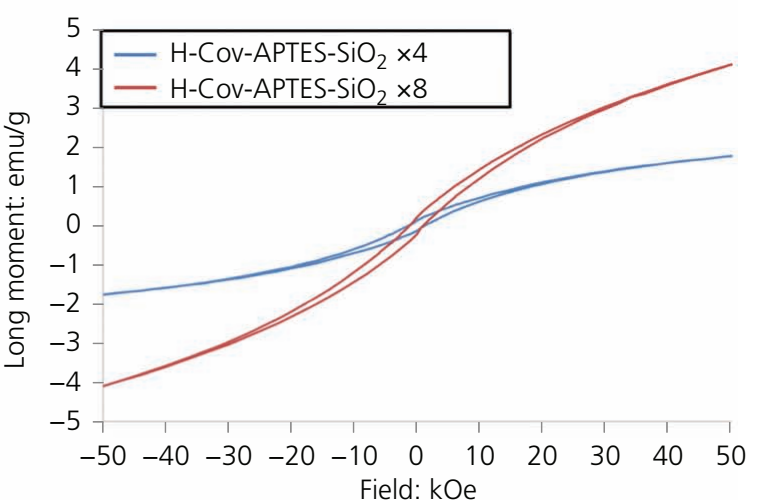

(b)

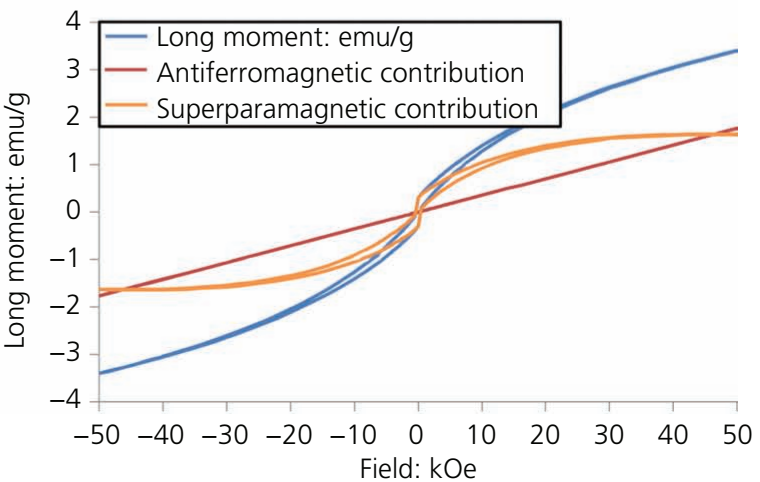

(d)

Figure 8. (a) The mineralized samples show a magnetic behavior, which was further characterized. (b) $M(H)$ hysteresis loops at $5 \mathrm{~K}$ of $\mathrm{H}$-Cov-APTES-SiO ${ }_{2}$ after four (blue) and eight (red) mineralization steps. (c) $\mathrm{M}(\mathrm{H})$ hysteresis loop of L-Cov-APTES-SiO ${ }_{2}$ at $5 \mathrm{~K}$ showing the original long moment (blue), the linear antiferromagnetic contribution (red) and the superparamagnetic contribution (orange). (d) $M(H)$ hysteresis loop of $\mathrm{H}$-COV-TESPSA-SiO 2 at $5 \mathrm{~K}$ the original long moment (blue), the linear antiferromagnetic contribution (red) and the superparamagnetic contribution (orange). The wasp-bellied shape suggests the presence of two distinct magnetic phases saturating at different field strengths 
immobilized on the surface could be attracted by a strong magnet (Figure 8(a)). Detailed measurements by a SQUID showed superparamagnetic behavior combined with a paramagnetic or antiferromagnetic contribution. Only the needles observed after mineralization without Fn also showed ferromagnetic behavior at room temperature. A combined superparamagnetic/antiferromagnetic behavior is also observed for native Fn and other antiferromagnetic nanoparticles. ${ }^{48,49}$ Observing the sample magnetization $M$ in dependence of the applied field strength $H$, the $M(H)$ curves show a linear contribution $\chi^{H}$ originating from a paramagnetic or antiferromagnetic phase. The linear contribution might originate from amorphous iron oxides which are not directly observed in the electron diffractograms. The second contribution comes from the maghemite/magnetite nanoparticles (Figure 8(c)). The presence of the hysteresis in the $M(H)$ curves at $5 \mathrm{~K}$ is a typical sign of the superparamagnetism of magnetite nanoparticles in the sub- $25 \mathrm{~nm}$ size range. ${ }^{50}$ Values of saturation magnetization and mass susceptibility could be shown to increase with the iron oxide content of the samples, as would be expected (Figure $8(\mathrm{~b})$ ). The $M(H)$ curves of all samples with Fn covalently bound to TESPSA show a wasp-bellied form (Figure 8(d)), presumably an overlay of the hysteresis curves of two particle size regimes, going into saturation at different magnetic field strengths. ${ }^{51}$ Measuring the samples' magnetic moment in dependence of the temperature at a low applied magnetic field provides information about the blocking temperature $\left(T_{\mathrm{b}}\right)$, below which the particles will show ferromagnetic behavior (Figure S7 in the online supplementary material). The peak in the ZFC curve which is characteristic of superparamagnetic samples gives an average $T_{\mathrm{b}}$ for each sample. For all investigated samples, $T_{\mathrm{b}}$ could be observed to increase with the number of mineralization cycles. While the increase in $T_{\mathrm{b}}$ from 48 to $52 \mathrm{~K}$ from the fourth to the eighth mineralization cycle is small in $\mathrm{H}-\mathrm{Cov}-\mathrm{APTES}-\mathrm{SiO}_{2}$, the increase in $\mathrm{H}-\mathrm{Cov}-\mathrm{TESPSA}-\mathrm{SiO}_{2}$ is more pronounced, rising from 31 to $79 \mathrm{~K}$. This comes not only from the particles growing in size with each step but also from an increase in the number of particles, as the relatively high blocking temperatures can also come from interaction between the particles. ${ }^{52}$ The close proximity of the iron oxide particles on the silica spheres may shift the blocking temperature to higher values as a result. This was also observed for other systems where interparticle distances were a few multiples of the particle diameter. ${ }^{53}$ It is notable that the blocking temperature of silica samples with H-Fn is always higher than the value observed with L-Fn after the same number of mineralization steps, which is the only hint that the mineralization capability of $\mathrm{H}-\mathrm{Fn}$ might be superior to L-Fn.

\section{Conclusion}

In conclusion, by immobilizing Fn homopolymers, magnetic films can be grown on stable and chemically inert surfaces. The covalent attachment of Fn with EDC/NHS cross-linking onto previously surface-functionalized silicon dioxide was found to be necessary for inducing the nucleation and growth of homogeneous iron oxide films. Physisorption most likely led to the adsorption of functional proteins at the surface, as shown in simulation experiments. However, the forces between the protein and surface are probably too low to maintain the function of the particle/protein unit during the whole mineralization procedure. According to the conformational analysis obtained by CD spectroscopy and BeStSel analysis, Fn undergoes structural changes upon adsorption and immobilization. Despite these structural changes, the mineralization experiments show that the samples with covalently bound H-Fn and L-Fn induce the formation of iron oxide nuclei with magnetite/maghemite as the main crystal phase. In this process, nucleation and crystal growth in solution are kinetically suppressed.

The obtained mineral phases are magnetically active, as shown by SQUID experiments. The hysteresis loops of the analyzed samples showed a superparamagnetic behavior combined with a paramagnetic contribution, which was confirmed obtaining the blocking temperature $T_{\mathrm{b}}$ through temperature-dependent magnetic moment measurements. The values are changing with the increase in the number and size of the iron oxide crystals on the particles after every mineralization cycle, but the superparamagnetism remains.

Utilizing the mineralization behavior of immobilized Fn homopolymers opens further possibilities for the fabrication of functional nanomaterials and 2D arrays with a potential for a broad range of magnetic, catalytic and biomedical sensing applications.

\section{Acknowledgements}

Helmut Cölfen (University of Konstanz) is thanked for providing the possibility of SQUID measurements; Thorsten Mehrtens and Marco Schowalter (Institute of Solid State Physics, University of Bremen) are gratefully acknowledged for the assistance in the HR-TEM and EDX analysis. The authors thank the Deutsche Forschungsgemeinschaft Priority Program 'Generation of Multifunctional Inorganic Materials by Molecular Bionics' (SPP 1569) for funding.

\section{REFERENCES}

1. Schüler D and Frankel RB (1999) Bacterial magnetosomes: microbiology, biomineralization and biotechnological applications. Applied Microbiology and Biotechnology 52(4): 464-473.

2. Arakaki A, Nakazawa H, Nemoto M, Mori T and Matsunaga T (2008) Formation of magnetite by bacteria and its application. Journal of the Royal Society Interface 5(6): 977-999.

3. Nancharaiah YV and Lens PNL (2015) Selenium biomineralization for biotechnological applications. Trends in Biotechnology 33(6): 323-330.

4. Douglas T, Strable E, Willits D et al. (2002) Protein engineering of a viral cage for constrained nanomaterials synthesis. Advanced Materials 14(6): 415-418.

5. Xu AW, Ma Y and Colfen H (2007) Biomimetic mineralization. Journal of Materials Chemistry 17: 415-449.

6. Baumgartner J, Dey A, Bomans PHH et al. (2013) Nucleation and growth of magnetite from solution. Nature Materials 12: 310-314.

7. Faivre D (2016) Iron Oxides: from Nature to Applications. Wiley$\mathrm{VCH}$, Weinheim, Germany.

8. Andrews SC (2010) The ferritin-like superfamily: evolution of the biological iron storeman from a rubrerythrin-like ancestor. Biochimica et Biophysica Acta (BBA) - General Subjects 1800(8): 691-705.

9. Arosio P, Elia L and Poli M (2017) Ferritin, cellular iron storage and regulation. IUBMB Life 69(6): 414-422. 
Bioinspired, Biomimetic and Nanobiomaterials Volume 8 Issue BBN1
Mineralization of iron oxide by ferritin homopolymers immobilized on $\mathrm{SiO}_{2}$ nanoparticles

Carmona, Treccani, Michaelis et al.
10. Carmona U, Li L, Zhang L and Knez M (2014) Ferritin light-chain subunits: key elements for the electron transfer across the protein cage. Chemical Communications 50: 15358-15361.

11. Volatron J, Carn F, Kolosnjaj-Tabi J et al. (2017) Ferritin protein regulates the degradation of iron oxide nanoparticles. Small 13(2) 1602030.

12. Carmona F, Poli M, Bertuzzi M et al. (2017) Study of ferritin self-assembly and heteropolymer formation by the use of fluorescence resonance energy transfer (FRET) technology. Biochimica et Biophysica Acta (BBA) - General Subjects 1861(3): $522-532$.

13. Uchida M, Kang S, Reichhardt C, Harlen K and Douglas T (2010) The ferritin superfamily: supramolecular templates for materials synthesis. Biochimica et Biophysica Acta (BBA) - General Subjects 1800(8): 834-845.

14. Kashanian S, Abasi Tarighat $F$, Rafipour $R$ and Abbasi-Tarighat $M$ (2012) Biomimetic synthesis and characterization of cobalt nanoparticles using apoferritin, and investigation of direct electron transfer of Co(NPs)-ferritin at modified glassy carbon electrode to design a novel nanobiosensor. Molecular Biology Reports 39(9): 8793-8802.

15. Pozzi C, Ciambellotti S, Bernacchioni C et al. (2017) Chemistry at the protein-mineral interface in 1-ferritin assists the assembly of a functional $\left(\mu^{3}\right.$-oxo)Tris $\left[\left(\mu^{2}\right.\right.$-peroxo $\left.)\right]$ triiron(III) cluster. Proceedings of the National Academy of Sciences of the United States of America 114(10): 2580-2585.

16. Matsui T, Matsukawa N, Iwahori K et al. (2007) Realizing a twodimensional ordered array of ferritin molecules directly on a solid surface utilizing carbonaceous material affinity peptides. Langmuir 23(4): 1615-1618.

17. Clemente-León M, Coronado E, Soriano-Portillo A et al. (2006) Magnetic Langmuir-Blodgett films of ferritin with different iron contents. Langmuir 22(16): 6993-7000.

18. Yuan Z, Petsev DN, Prevo BG, Velev OD and Atanassov P (2007) Twodimensional nanoparticle arrays derived from ferritin monolayers. Langmuir 23(10): 5498-5504.

19. Sam S, Touahir L, Salvador Andresa J et al. (2010) Semiquantitative study of the EDC/NHS activation of acid terminal groups at modified porous silicon surfaces. Langmuir 26(2): 809-814.

20. Kroll S, Brandes C, Wehling J et al. (2012) Highly efficient enzymefunctionalized porous zirconia microtubes for bacteria filtration. Environmental Science \& Technology 46(16): 8739-8747.

21. Halfer T, Rei A, Ciacchi LC, Treccani L and Rezwan K (2014) Selective covalent immobilization of ferritin on alumina. Biointerphases $\mathbf{9 ( 3 )}$ : 031018.

22. Meder F, Daberkow T, Treccani L et al. (2012) Protein adsorption on colloidal alumina particles functionalized with amino, carboxyl, sulfonate and phosphate groups. Acta Biomaterialia 8(3): 1221-1229.

23. Meldrum F, Heywood B and Mann S (1992) Magnetoferritin: in vitro synthesis of a novel magnetic protein. Science 257(5069): 522-523.

24. Wong KKW, Douglas T, Gider S, Awschalom DD and Mann S (1998) Biomimetic synthesis and characterization of magnetic proteins (magnetoferritin). Chemistry of Materials 10(1): 279-285.

25. Meldrum FC, Douglas T, Levi S, Arosio P and Mann S (1995) Reconstitution of manganese oxide cores in horse spleen and recombinant ferritins. Journal of Inorganic Biochemistry 58(1): $59-68$

26. Hoffmann F, Cornelius M, Morell J and Fröba M (2006) Silica-based mesoporous organic-inorganic hybrid materials. Angewandte Chemie International Edition 45(20): 3216-3251.

27. Balas F, Manzano M, Colilla M and Vallet-Regí M (2008) 1-Trp adsorption into silica mesoporous materials to promote bone formation. Acta Biomaterialia 4(3): 514-522.

28. Nieto A, Balas F, Colilla M, Manzano M and Vallet-Regí M (2008) Functionalization degree of SBA-15 as key factor to modulate sodium alendronate dosage. Microporous and Mesoporous Materials 116(1-3): 4-13.

29. Nieto A, Colilla M, Balas F and Vallet-Regí M (2010) Surface electrochemistry of mesoporous silicas as a key factor in the design of tailored delivery devices. Langmuir 26(7): 5038-5049.

30. Greenfield NJ (2006) Using circular dichroism spectra to estimate protein secondary structure. Nature Protocols 1: 2876-2890.

31. Anthis NJ and Clore GM (2013) Sequence-specific determination of protein and peptide concentrations by absorbance at $205 \mathrm{~nm}$. Protein Science 22(6): 851-858

32. Kuipers BJH and Gruppen H (2007) Prediction of molar extinction coefficients of proteins and peptides using UV absorption of the constituent amino acids at $214 \mathrm{~nm}$ to enable quantitative reverse phase high-performance liquid chromatography-mass spectrometry analysis. Journal of Agricultural and Food Chemistry 55(14): 5445-5451.

33. Micsonai A, Wien F, Kernya L et al. (2015) Accurate secondary structure prediction and fold recognition for circular dichroism spectroscopy. Proceedings of the National Academy of Sciences of the United States of America 112(24): E3095-E3103.

34. Anandakrishnan R, Aguilar B and Onufriev AV (2012) $H++3.0$ : automating $\mathrm{pK}$ prediction and the preparation of biomolecular structures for atomistic molecular modeling and simulations. Nucleic Acids Research 40(W1): W537-W541.

35. Myers J, Grothaus G, Narayanan S and Onufriev A (2006) A simple clustering algorithm can be accurate enough for use in calculations of $\mathrm{pKs}$ in macromolecules. Proteins: Structure, Function, and Bioinformatics 63(4): 928-938.

36. Gordon JC, Myers JB, Folta T et al. (2005) H++: a server for estimating $\mathrm{p} K_{\mathrm{a}} \mathrm{s}$ and adding missing hydrogens to macromolecules. Nucleic Acids Research 33(Suppl 2): W368-W371.

37. Cole DJ, Payne MC, Csányi G, Spearing SM and Ciacchi LC (2007) Development of a classical force field for the oxidized Si surface: application to hydrophilic wafer bonding. Journal of Chemical Physics 127(20): 204704.

38. Sonnefeld J (1995) Surface charge density on spherical silica particles in aqueous alkali chloride solutions. Colloid and Polymer Science 273(10): 932-938.

39. Dove PM and Craven CM (2005) Surface charge density on silica in alkali and alkaline earth chloride electrolyte solutions. Geochimica et Cosmochimica Acta 69(21): 4963-4970.

40. Kobayashi M, Juillerat F, Galletto P, Bowen P and Borkovec M (2005) Aggregation and charging of colloidal silica particles: effect of particle size. Langmuir 21(13): 5761-5769.

41. Legrand APGY, Burneau A, Papirer E and Fubini B (1998) The Surface Properties of Silicas. Wiley, New York, NY, USA.

42. Case DA, Darden T, Cheatham TE III et al. (2012) Amber 12 University of California San Francisco, San Francisco, CA, USA.

43. Onufriev A, Bashford D and Case DA (2004) Exploring protein native states and large-scale conformational changes with a modified generalized Born model. Proteins: Structure, Function, and Bioinformatics 55(2): 383-394.

44. Butenuth A, Moras G, Schneider J et al. (2012) Ab initio derived force-field parameters for molecular dynamics simulations of deprotonated amorphous- $\mathrm{SiO}_{2} /$ water interfaces. Physica Status Solidi B 249(2): 292-305.

45. Humphrey W, Dalke A and Schulten K (1996) VMD: Visual Molecular Dynamics. Journal of Molecular Graphics 14(1): 33-38.

46. Hildebrand N, Köppen S, Derr L et al. (2015) Adsorption orientation and binding motifs of lysozyme and chymotrypsin on amorphous silica. Journal of Physical Chemistry C 119(13): 7295-7307.

47. Santoyo Salazar J, Perez L, de Abril O et al. (2011) Magnetic iron oxide nanoparticles in 10-40 $\mathrm{nm}$ range: composition in terms of magnetite/maghemite ratio and effect on the magnetic properties. Chemistry of Materials 23(6): 1379-1386. 
Bioinspired, Biomimetic and Nanobiomaterials Volume 8 Issue BBN1
Mineralization of iron oxide by ferritin homopolymers immobilized on $\mathrm{SiO}_{2}$

nanoparticles

Carmona, Treccani, Michaelis et al.
48. Kilcoyne SH and Cywinski R (1995) Ferritin: a model superparamagnet. Journal of Magnetism and Magnetic Materials 140-144(2): 1466-1467.

49. Silva NJO, Amaral VS, Carlos LD and de Zea Bermudez V (2004) Ferrihydrite antiferromagnetic nanoparticles in a sol-gel derived organic-inorganic matrix. Journal of Magnetism and Magnetic Materials 272-276(2): 1549-1550.

50. Piper JDA, Dunlop DJ and Özdemir Ö (1997) Rock Magnetism: Fundamentals and Frontiers. Cambridge University Press, Cambridge, UK.
51. Brem F, Tiefenauer L, Fink A, Dobson J and Hirt AM (2006) A mixture of ferritin and magnetite nanoparticles mimics the magnetic properties of human brain tissue. Physical Review B 73(22): 224427-1-224427-6.

52. Mørup S, Hansen MF and Frandsen C (2010) Magnetic interactions between nanoparticles. Beilstein Journal of Nanotechnology 1: 182-190.

53. Tronc $E$, Prene $P$, Jolivet JP et al. (1995) Magnetic behaviour of $\gamma-\mathrm{Fe}_{2} \mathrm{O}_{3}$ nanoparticles by Mössbauer spectroscopy and magnetic measurements. Hyperfine Interactions 95(1): 129-148.

\section{How can you contribute?}

To discuss this paper, please submit up to 500 words to the journal office at journals@ice.org.uk. Your contribution will be forwarded to the author(s) for a reply and, if considered appropriate by the editor-in-chief, it will be published as a discussion in a future issue of the journal.

ICE Science journals rely entirely on contributions from the field of materials science and engineering. Information about how to submit your paper online is available at www.icevirtuallibrary.com/page/authors, where you will also find detailed author guidelines. 